\title{
Vulnerability, food aid, and dependency Views from development geography
}

Miriam Wenner

The relations between vulnerability, dependency, and the ideal of autonomous personhood are fraught with tension. As Whitney ${ }^{1}$ notes, our imaginations of a "good" person are grounded in normative assumptions of independence and autonomy, which she draws back to the Hobbesian contention that dependency always meant domination over subjects who therefore must try to avoid it by striving for independence and liberty. Fineman ${ }^{2}$ adds that this "fiction ${ }^{3}$ of the autonomous subject stands today at the heart of political, juridi$\mathrm{cal}$, and economical policies that assume an evenness of actors while ignoring the structural unevenness of a globalised world order. ${ }^{4}$

Several authors challenge such thinking by arguing that vulnerability is a basic condition of human life: it is universal (all humans are vulnerable) and particular (some are more vulnerable than others). ${ }^{5}$ Dependency on others is thus unavoidable. Replacing the assumption of the liberal subject with the one of a vulnerable subject avoids rendering dependency and vulnerability as deviations from a seemingly normal, liberal state and thereby frees it from its negative connotations. This realisation calls for a moral change in politics geared towards addressing vulnerability and building resilience. ${ }^{6}$ Critical authors claim that the labelling and stigmatising of certain populations as "vulnerable" not only mark them as imperfect, but also promote surveillance and regulation while obscuring differences between individuals. ${ }^{7}$ Instead, they call for a policy that addresses the

\footnotetext{
1 Shiloh Y. Whitney, Dependency Relations: Corporeal Vulnerability and Norms of Personhood in Hobbes and Kittay, Hypatia, 26 (2011), 554-574.

2 Martha Albertson Fineman, Equality, Autonomy, and the Vulnerable Subject in Law and Politics, in:Vulnerability. Reflections on a New Ethical Foundation for Law and Politics, ed. by Martha Albertson Fineman and Anna Grear, Surrey/Burlington 2013, 13-28.

3 Ibid., 16.

4 Martha Albertson Fineman/Anna Grear, Introduction. Vulnerability as Heuristic. An Invitation to Future Exploration, in: Fineman/Grear (eds.), Vulnerability, 1-12.

5 Fineman/Grear (eds.), Vulnerability; Shiloh Y. Whitney, Dependency Relation; Sarah Atkinson/Victoria Lawson/Janine Wiles, Care of the Body: Spaces of Practice, in: Social \& Cultural Geography, 12 (2011), 563-572.

6 Fineman/Grear (eds.),Vulnerability, 1-12.

7 Ibid., 16
} 
structural conditions leading to an unequal distribution of vulnerability around the globe, within countries, societies, and households. While for these authors dependency is the natural companion of human vulnerability, in the following discussion I will complicate this perception by showing how different forms of dependency can both increase and decrease vulnerability.

While the above-described discourses juxtapose notions of autonomous personhood, vulnerability, and dependency in the context of North American state welfare policy, the domain of development assistance has long recognised vulnerability as a basic condition of its "target groups". In reference to so-called "developing countries" or the "Global South", the talk of "vulnerability" and "resilience" has long entered the policy dictionaries of states, agencies, and donors who attempt to foster "development " in terms of self-reliance, sustainability, and well-being. ${ }^{8}$ Such interventions are supported by conceptual and methodological frameworks that serve to identify "vulnerable populations".

While the ethical bases of interventions based on such labelling are hardly ever questioned within the donor community, there is yet a permanent fear that interventions geared at reducing vulnerability of recipients might create "dependency " of aid-recipients. Aid, it is feared, could result in a "dependency syndrome", expressing the belief that a group loses its ability and willingness to solve its problems independently, without the help of external aid. ${ }^{9}$ Accordingly, instead of reducing vulnerability, interventions could increase vulnerability in the longer-term.

This paper takes these tensions as a starting point to explore the relations between vulnerability and dependency in the field of development assistance. Going beyond a discussion of discursive »buzzwords ${ }^{10}$, I will focus on an empirical case of a food-for-work programme implemented by the United Nations World Food Programme (WFP) in a remote region of Nepal.

How are the problematic relations between vulnerability, dependency, and food security taken into account in humanitarian interventions? What are the ethical implications of these tense relationships for food aid and broader state policy? This essay will also address how vulnerability and dependency are experienced by those identified as "needy". The discussion aims at bringing together those

8 Amy Kaler/John R. Parkins, Food, Donors, and Dependency Syndrome(s) in South Sudan, in: Sociology of Development, 1 (2015), 400-416.

9 Ibid.

${ }^{10}$ Ibid. 
modern age philosophical approaches that describe vulnerability as a deviation from the ideal of autonomous personhood and approaches to vulnerability as employed in geographical development studies, asking what we can learn about the latter when approached through the former.

The case study is based on fieldwork that I conducted in Nepal in spring and summer 2009. At first, an internship with the WFP Nepal introduced me to Mugu district, a mountainous region in north-western Nepal bordering Tibet that was at that time not accessible by road. In summer 2009, I returned to the region for a six-week long independent field research focusing on one village that had recurrently received food assistance under a food-for-work scheme. Data were generated through a mix of qualitative interviews and participatory methods with villagers, interviews with NGO staff, government and WFP workers, and a quantitative sample survey in the village. While the study aimed at a realist exploration of the effects of food assistance on households' livelihoods and possible creation of dependency on the WFP, I now try to juxtapose these findings with discussions on the normative assumptions of personhood.

\section{Vulnerability and liberal personhood in development geography}

In development studies vulnerability emerged as a concept intended to replace economically informed definitions of poverty with an approach that accounted for different dimensions of deprivation. ${ }^{11}$ Vulnerability refers to a subject's (household, individual, system) susceptibility to harm from an exposure to risk or external perturbance. It is a function of (i) exposure to risk, (ii) the ability to cope, and (iii) the potential to recover from induced losses. ${ }^{12}$ In contrast to vulnerability applications in climate change research that tend to view it as a property of socio-ecological systems, ${ }^{13}$ vulnerability in the context of poverty and livelihoods focuses on the practices of households

\footnotetext{
${ }^{11}$ Robert Chambers, Vulnerability. Coping and Policy, in: IDS Bulletin 37 (1989), 33-40, here 33.

${ }^{12}$ Michael J. Watts/Hans-Georg Bohle, Hunger, Famine and the Space of Vulnerability, in: GeoJournal 30 (1993), 117-125.

${ }_{13}$ W. Neil Adger, Vulnerability, in: Global Environmental Change 16 (2006), 268281; Billie Lee Turner II/Roger E. Kasperson/Pamela A. Matson/James J. McCarthy/ Robert W. Corell/Lindsey Christensen and others, A Framework for Vulnerability Analysis in Sustainability Science, in: PNAS 100 (2003), 8074-8079.
} 
and individuals as actors who attempt to survive or increase their well-being in given situations and contexts. ${ }^{14}$

The aim is to explain the differential degrees of vulnerability amongst individuals and populations grounded in the acknowledgement that ways and capacities to cope with stress and contingency are shaped by conditions often outside of actors' influence. The space of vulnerability is defined by "locally and historically specific configurations of poverty «. ${ }^{15}$ Thus, a main conceptual interest of these approaches concerns the dialectic relations between structural conditions (such as formal/informal rules, social and cultural norms, economic, political, and ecological trends) and human agency. ${ }^{16}$ In contrast to liberal-normative assumptions of vulnerability, in development studies those vulnerable are not blamed for their misery, but rather seen as power-less and marginalised victims of broader social, political, and economic processes, trying the best they can to survive.

In this way, vulnerability approaches acknowledge limitations to individual agency, autonomy, and liberty that normative assumptions of liberal personhood presume. Instead, subjects' room for manoeuvre is always regarded as already embedded in, constrained by, or enabled by external conditions. Dependency is acknowledged as a basic condition of human life. It can be enabling as well as disabling. Subjects are acknowledged as already and always standing in relation to other persons and processes. The ideal person then is not a person who can survive independently from such context - rather, it would be a person who can make use of it in the most beneficial ways. Conversely, the ideal situation would be one where the structures are enabling and not constraining human agency for survival and well-being.

\section{Food security, food aid, and dependency}

While in sociological theorisations of vulnerability the dependence of subjects on others and external structures is seen as both enabling and disabling, in development practice dependency is regarded as

\footnotetext{
${ }^{14}$ Hans-Georg Bohle, Living with Vulnerability. Livelihoods and Human Security in Risky Environments, Bonn 2007; Matthew D. Turner, Climate Vulnerability as a Relational Concept, in: Geoforum 68 (2016), 29-38; Ben Wisner and others, At Risk: Natural Hazards, People's Vulnerability and Disasters, London 2004.

${ }^{15}$ Watts/Bohle, Hunger, Famine, and the Space of Vulnerability, 117.

${ }^{16}$ Anthony Giddens, The Constitution of Society. Outline of the Theory of Structuration, Cambridge 1984.
} 
something negative and to be avoided. At a local level, this especially concerns the creation of a so-called "dependency syndrome ${ }^{17}$ (see above).

Opposing such value-laden, negative descriptions of dependency, Harvey and Lind ${ }^{18}$ defined persons as aid-dependent "when they cannot meet immediate basic needs in the absence of relief assistance ${ }^{19}$. Lentz et $\mathrm{al}^{20}$ (in a study for the WFP) added that dependency can be both positive and negative. "Positive dependency « supports households and persons to meet their basic needs for survival; external provision of relief can for instance enable victims of natural disasters to maintain their basic assets instead of selling them in times of crisis, and thereby support their recovery. In contrast, "negative dependency" occurs "when meeting current needs is achieved at the cost of reducing recipients' capacity to meet their own basic needs in the future without external assistance ${ }^{21}$, a definition reflecting the "dependency syndrome».

Allegations of dependency creation have been especially pronounced in the domain of food aid. To better analyse the different intended and unintended consequences of food aid on recipients, Lentz et $\mathrm{a}^{12}$ propose a distinction of so-called »insurance " and "transfer-effects", grounded in an economistic model of the rational actor responding to stimuli. Insurance-effects appear prior to the distribution of aid. Expectations of food aid might weaken existing insurance mechanisms such as social networks, and lead to increased risk-taking (which can be evaluated as positive or negative). While insurance-effects appear prior to the actual distribution of aid, and are directly related to transparency and reliability of external transfers, transfer-effects happen after the flow. While the actual transfer of food aid (in kind or cash) can help households to preserve their assets (seeds, livestock, land, money), some warn from its distorting effects on markets. Food aid in kind might insert a downward pressure on food prices, displace commercial purchases and create disincentives for local food production. It might change food con-

\footnotetext{
${ }^{17}$ Kaler/Parkins, Food, Donors, and Dependency Syndrome(s) in South Sudan, 400.

${ }^{18}$ Paul Harvey/Jeremy Lind, Dependency and Humanitarian Relief. A Critical Analysis. HPG Report 19, London 2005.

${ }^{19}$ Ibid., 3.

${ }^{20}$ Erin C. Lentz/Christopher B. Barrett/John Hoddinott, Desk Review: Food Aid and Dependency: Implications for Emergency Food Security Assessments, Rome: World Food Programme, 2005.

${ }^{21}$ Ibid., 12.

${ }^{22}$ Ibid.
} 
sumption habits, induce laziness and decrease initiative to build self-sufficient livelihoods. ${ }^{23}$

The actual effects of food aid on individuals' behaviour can appear simultaneously and differ for different persons (traders, poor farmers, rich farmers, landless, etc.).

Partly in contrast to opinions about the liberal subject, the introduced dependency model acknowledges the life-saving function of short-term dependency in situations of distress, thereby justifying humanitarian interventions. At the same time, however, the model cautions against the longer-term detrimental effects of food aid that risk undermining the self-initiative and autonomy of recipients. Underlying this fear is the normative assumption of an ideal recipient who should only rely on aid in times of extreme crises (which are defined and labelled by governments and agencies) and otherwise be striving for self-reliance and autonomy. Thereby, and in contrast to above described vulnerability approaches, the economistic model based on incentives and disincentives tends to obscure the importance of structural conditions that enable or hinder persons to live a self-determined and independent live. This is problematic, as accusations of creating dependency have served agencies to withdraw from their life-saving engagement in several contexts. ${ }^{24}$ This underlines the power of dependency as a buzzword in development practice and an excuse for certain policies.

Harvey and Lind, ${ }^{25}$ however, express caution against such assumptions of liberal personhood. Drawing on Dean ${ }^{26}$ they explicitly acknowledge inter-dependency of humans: here, all members of a community are part of complex webs of relationships and dependencies, a point I return to in the case study.

Drawing at distinctions between positive and negative dependency and the concept of insurance and transfer effects I now examine whether development interventions aimed at reducing the vulnerability of recipients have the reverse effect by creating negative dependency.

\footnotetext{
${ }^{23}$ Christopher B. Barrett, Food Aid's Intended and Unintended Consequences, ESA Working Paper No. 06-05, Rome 2006.

${ }^{24}$ Harvey/Lind, Dependency and humanitarian relief.

${ }^{25}$ Ibid.

${ }^{26}$ H. Dean (ed.), The Ethics of Welfare. Human Rights, Dependency and Responsibility, Bristol 2004.
} 


\section{Dependency, vulnerability, and food aid in Nepal}

As in other countries, the assumption that food aid creates dependency of recipients is also widespread in Nepal and allegedly becomes visible in changing food habits of recipients, a decline of social relations, and increasing "laziness " of those who are waiting for a presumably free provision of rice and lentils. ${ }^{27}$ Such accusations are mainly directed against the WFP that functions as the largest provider of food assistance in Nepal. But was an intervention intended to address food insecurity indeed creating dependency? I now present the results of an empirical study on the effects that a food-for-work (FFW) programme had in a highly food insecure region in the north-western district of Mugu. FFW are labour-intensive infrastructure works undertaken by the target population in exchange for food grain. In contrast to immediate humanitarian assistance which does not have any direct intention to foster development, FFW can be considered belonging to "project aid" that also has a developmental focus.

\section{Food insecurity in Mugu: access, availability, and utilisation}

The FAO defines food security as "a situation that exists when all people, at all times, have physical, social and economic access to sufficient, safe and nutritious food that meets their dietary needs and food preferences for an active and healthy life $\ll^{28}$. While availability of food is a necessary condition for food security, the access to food and the ability to utilise it are equally (if not more) important. Food security is thus largely an outcome of what $\mathrm{Sen}^{29}$ called "entitlements", or the set of alternative commodity bundles that allow people to access food, enshrined in broader structures of political economy, citizenship, and social contract. ${ }^{30}$ Food security is one dimension of

\footnotetext{
${ }^{27}$ Yamuna Ghale, Role of Agriculture in Securing Food for All, in: Nepali Times 16 October 2009 (Fund Insecurity), 548 (2011), available at http://nepalitimes.com/ news.php?id=18104\#.WDcFjZLKMnl; Nepali Times, The Trade of Aid, Nepali Times, 548 (2011), available at http://nepalitimes.com/news.php?id=18092\#.WDcFRJLKMnk.

${ }^{28}$ FAO, The State of Food Insecurity in the World 2001. Food Insecurity: When People Live with Hunger and Fear Starvation, Rome 2002, 49.

${ }^{29}$ Amartya Sen, Poverty and Famines: An Essay on Entitlements and Deprivation, Oxford 1981.

${ }^{30}$ Michael Watts, Hour of Darkness:Vulnerability, Security and Globalization, in: Geographica Helvetica 57 (2000), 5-18; Watts/Bohle, Hunger, Famine and the Space of
} 
human security and thereby a prerequisite for human development, or the "process of enlarging people's choices ${ }^{31}{ }^{31}$ In other words: to be an autonomous and self-sufficient human being able to make independent decisions on his/her life, one needs to have food security (besides other securities). Being enshrined in the 1948 declaration of human rights, the "right to food " approach increasingly enters public discourse, such as in India, where the government passed a "Right to Food Act« in 2013.

For many people living in the remote Mugu district, human and food security appear like far-away dreams. The district, which in 2011 ranked amongst the last in terms of human development in Nepal (0.397 vs 0.490), has extremely high numbers of child undernourishment (half of children under five). ${ }^{32}$ Continuing a legacy of historical marginalisation within Nepal, ${ }^{33}$ at the time of research Mugu was only connected to the rest of the country via a gravel-air field or via foot paths through the steep and high-altitude terrain.

While subsistence agriculture and animal husbandry build the main livelihood base of the largely rural population, productivity is low due to exposure to the vagaries of weather, lack of irrigation facilities and improved seeds, and the small size of landholdings. In addition to the low production-based entitlements, access to food through exchange or purchase is limited owing to a lack of markets, high prices, and low incomes.

In response to these adverse conditions, villagers in Ruga, where I studied the effects of FFW had developed a range of livelihood strategies that helped them make ends meet. While better-off and educated persons found employment with NGOs or the government, others engaged in manual labour, or in erratic daily-wage labour for example in agriculture, portering or stone breaking, in addition to fishing, collection and (illegal) sale of firewood, or bee farming. Seasonally, incomes were complemented with the collection and sale of wild herbs and medical plants, the prices of which depended on local middlemen. At times, people would purchase food from lower-lying areas where it is cheaper, or from the governmental Nepal Food Corporation (NFC) which sells food at subsidised rates. Access to the latter was, however, perceived highly exclusive

\footnotetext{
Vulnerability.

${ }^{31}$ UNDP, Human Development Report. Concept and Measurement of Human Development, Oxford 1990, 10.

${ }^{32}$ Government of Nepal/UNDP, Nepal Human Development Report 2014. Beyond Geography. Unlocking Human Potential, Kathmandu 2014.

${ }^{33}$ Jagannath Adhikari, Food Crisis in Karnali. A Historical and Politico-Economic Perspective, Kathmandu 2008.
} 
and depending on contacts to the administration or political parties. Against the backdrop of such uncertainty, villagers relied on their social networks including neighbours, relatives, spiritual friendships, or traditional patron-client ties. Nearly all households asked about the nearest source of support during acute food shortages mentioned their neighbours, underlining the importance of such transfer entitlements. If the aforementioned sources of food fail, many male household members decide to migrate to India for work, although they try to return for field-work.

Yet, during acute food crisis, people employed a range of detrimental coping strategies, including reduced food consumption (mainly women), consumption of seeds, or taking children out of school to send them to work. Especially the sale of assets such as livestock or taking loans are considered detrimental as they weaken the capacities to achieve food security in the longer-term. Such severe strategies were mainly employed by the poorest members of the community.

Comparing households' endowment with assets (land, financial capital, education) and reliance on different coping strategies underlined that members of the village community were characterised by different degrees of vulnerability to food insecurity. Those were most vulnerable with low domestic food production, who lacked sufficient and regular income to purchase food at the market, who lacked the physical strength to purchase cheaper food from places further away, who lacked necessary networks to migrate, education to obtain higher salaries, and personal ties to government agencies such as the NFC or political parties. ${ }^{34}$

\section{Food aid, dependency, and webs of interdependence}

The above brief description of the entitlements available to residents of Ruga indicates that their food security relies on a variety of food sources. Elsewhere I argue that these entitlement sets can be regarded as networks of interdependence between persons and places. ${ }^{35}$ They become visible in the form of mutual help between villagers, patron-client systems, the relations to the state (in form of the NFC), or in relations between employers (in and outside of Mugu and Nepal) and employees. While knowing that they relied on these networks stretching over social groups and geographical

\footnotetext{
${ }^{34}$ Miriam Wenner [Bishokarma], Assessing »dependency«. Food security and the impacts of food aid on livelihoods in Mugu, Kathmandu 2012.

${ }_{35}$ Ibid.
} 
space, villagers often disliked depending on certain persons or food sources as they were not always reliable. Dependence was sometimes associated with a feeling of shame.

Food aid must be understood within these already existing interdependencies. Although at the time of research in the village no FFW programme was ongoing, it had received assistance several times before. Throughout, villagers assigned an important role to food aid during its distribution, some even designating it as the most important source of food. In terms of accessibility, however, food aid was largely perceived as unreliable and its distribution intransparent. Villagers did not know whether and when they would be entitled to food aid programmes; all they could do was to hope and frequently stress their need for assistance. This apparent lack of information and reliability clearly reduced the insurance-effect. Instead, social networks and the outspoken need to engage in domestic crop production remained important livelihood strategies.

In contrast, transfer effects became visible in increased food availability and sufficiency of households. However, villagers criticised that the amount of food distributed was hardly sufficient to feed their families for a prolonged period of time, underlining the importance of other sources of food besides food aid. Interviews also revealed that food aid helped households to retain their productive assets instead of selling them in times of crisis. This includes the protection of the natural resource base as villagers' reliance on illegal sales of firewood was reduced. FFW also stopped some villagers from migrating to India. Contrary to assumptions that social networks declined due to food aid, villagers felt that cooperation in FFW increased their community feeling; the fact that all households gained resources through the FFW also increased the ability for community sharing.

Negative effects of FFW were noticed in terms of time-constraints as participation in FFW sometimes stopped villagers from attending their own field works, and the decreased willingness to participate in local-government induced community works as the payment was lower compared to FFW.

Interestingly, however, what seemed to determine the perceived importance of food aid was less its amount but rather how it related to and complemented other available food sources. For instance, food aid had effects on the already existing interdependencies. Most visible, it partly dissolved existing dependency relationships by decreasing the need for employment in exploitative relationships (e.g. labour migration). Villagers also noted an increase in wages as their higher 
entitlement in FFW increased their bargaining power. Further, many stressed the perceived egalitarian nature of distribution in the village (once, it was selected for a programme) in contrast to the exclusive NFC. Also the fact that members of different castes worked and ate together during FFW programmes eased caste-based discrimination. Community solidarity became also visible in villagers' decision that all households of their community should participate in FFW which challenged WFP's earlier policy that $20 \%$ of households should be excluded as part of the targeting. Now, all households can participate.

Thus, although villagers maintained that they could survive without food aid somehow, it increased their well-being and feeling of security as food aid was easier accessible compared to other sources.

In summary, far from being an alien challenge to existing forms of livelihoods, strategies, and social networks, food assistance became incorporated in already existing networks of dependencies. It became an additional entitlement that expanded and complemented these networks and helped recipients to rely on it during crisis. One villager described this as follows: "First of all, we depend on our own production. If this fails, we depend on the WFP. If this does not come, we depend on the NFC [...] We always depend on the source which is easiest available and accessible." Yet, it would be wrong to claim that the existing entitlements are sufficient, as the reliance on sometimes detrimental coping strategies underlines. Food aid then can help to support recipients' well-being by providing an easier means of survival.

A second finding is that the degree of dependency on food aid differs between the villagers. The more difficult the access to other sources of food the greater the dependence on food aid becomes.

Incentives and disincentives are ultimately determined by food aid's unreliability. Food aid, thus, is not a fixed, monolith structure; it rather takes the character of a dynamic institution that villagers anticipate full of hope and expectation. The villagers' decision whether and how much to rely on food aid is thus framed by the ever-lasting tension between anticipation and the intransparency of food aid deliveries and policies. Far from being passive and »lazy« recipients of food aid, they need to navigate not only the vagaries of the weather, market and exchange relations, but also the vagaries of food aid with the aim of survival. It is in this navigation that they maintain their autonomy as subjects. 


\section{Creating spaces that enable positive dependency}

It is the outspoken aim of the WFP to »end global hunger « ${ }^{36}$. Amongst the four objectives in the current strategic plan (2014-2017) is to "[r]educe risk and enable people, communities and countries to meet their own food and nutrition needs ${ }^{37}$. Judged against the prevailing hunger worldwide and in places like Mugu, the WFP still has a long way to go to achieve this. Indeed, the question of the developmental effectiveness of food aid interventions looms large over the WFP, and underlines that food aid alone cannot be a sufficient means to stop worldwide hunger. Also recipients of aid in Mugu criticised the lack of long-lasting developmental effects through FFW. Food aid could not stop droughts from happening, and it could not build a road to connect the remote region with the lower-lying markets. It could not build an irrigation facility that would help villagers to increase yields from domestic crop production. It could not build hospitals and bring doctors to the region, nor bring the government closer to people. Thus, while it could not seriously change the exposure of people to contingencies, it did help them cope by complementing already existing networks of dependency on a variety of food sources. Food aid helped reduce recipients' vulnerability by allowing them to keep their productive assets and to maintain a certain level of nutrition. Instead of creating "negative dependency«, food aid complemented rather than replaced other already existing interdependencies that made up persons' food entitlements.

The introduced distinction between positive and negative dependency helped to understand the former as enabling rather than disabling autonomy. It enables people to live a life more according to their own preferences, e.g. the dependence on one food source before the other. It can help them to break free from those relations that they perceive as oppressive and exploitative, to substitute these with relations they regard as better and more just. While acknowledging that vulnerability as a basic human condition can never be eliminated, positive dependency can reduce it. The discussion suggested that the human embedding and interdependence with broader social, environmental, and political structures does not only bear risks but can also be enabling. Far from propagating the self-dependent and autonomous individual, recognising dependency as enabling demands policies and developmental interventions that

${ }^{36}$ WFP 2016. About. Strategic plan, available at http://www.wfp.org/about/strategic-plan (24.11.2016).

${ }^{37}$ Ibid. 
enable dependency on them. This includes transparency and reliability as a way to reduce uncertainty so that persons can incorporate external support into their livelihood strategies.

The above discussion underlined that any attempts to address vulnerability will not succeed without addressing the broader structural constraints that frame both, people's exposure to risk and stress, and their abilities to cope with them. A reduction in vulnerability calls for constructing enabling structures. Considering vulnerability a universal characteristic of humans, greater autonomy and self-reliance can only be achieved in spaces that foster interdependencies, trust, and care for each other, at the local, national, and the global level. ${ }^{38}$

- Miriam Wenner is a post-doctoral researcher in Human Geography at the University of Zurich. Besides studying different processes associated with »development « she is interested in the ways that moral values influence politics, economy, and society in South Asia.

\footnotetext{
${ }^{38} \mathrm{I}$ am very grateful to Johanna Breidenbach for her helpful and critical comments and to Craig Hatcher for proofreading.
} 